\title{
Characteristics of gut microbiome, organic acid profiles and viral antibody indexes of healthy Japanese with live Lacticaseibacillus detected in stool
}

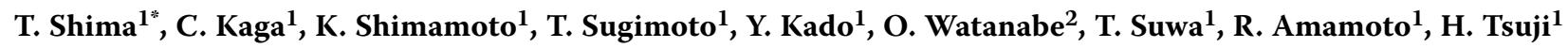 \\ and S. Matsumoto ${ }^{1}$ \\ ${ }^{1}$ Yakult Central Institute, 5-11 Izumi, Kunitachi-shi, Tokyo 186-8650, Japan; ${ }^{2}$ Yakult Honsha Co. Ltd., Development \\ Department, 1-10-30 Kaigan, Minato-ku, Tokyo 105-8660, Japan; tatsuichiro-shima@yakult.co.jp
}

Received: 20 July 2021 / Accepted: 18 December 2021

(c) 2022 Wageningen Academic Publishers

\section{OPEN ACCESS @(1)(-) RESEARCH ARTICLE}

\begin{abstract}
To estimate the health-promoting effects of Lacticaseibacillus paracasei (previously Lactobacillus casei) strain Shirota (LcS) that reached the lower gastrointestinal tract alive, we investigated the characteristics of gut microbiome, organic acid profiles, defecatory symptoms and serum viral antibody indexes of healthy Japanese adults between the group in whom live LcS was detected or not from stool. The $\beta$-diversity index of the gut microbiome constituted a significant difference between the live-LcS-detected-group (LLD) and the live-LcS-not-detected-group (LLnD). In the LLD, the Bifidobacteriaceae, Lactobacillaceae, and Coriobacteriaceae counts were significantly higher, and the succinate concentration was significantly lower than that in the LLnD. The serum herpes simplex virus (HSV) immunoglobulin (Ig)M antibody index in the LLD tended to be lower than that of the LLnD in HSV IgG-positive subjects. Of the LLD, those in the fermented milk products containing LcS (FML)-high-frequency-group (FMLHF) and those in the FML-low-frequency-group (FML-LF) had different gut microbiome and organic acid profiles. However, the pattern of differences between FML-HF and FML-LF was dissimilar those between LLD and LLnD. In contrast, among subjects with FML-LF, those in the group with LLD in stool (LF-LLD) and those in the LLnD in stool (LF-LLnD) showed a similar pattern of differences in their gut microbiome and organic acid profiles as those in the LLnD and LLD. The LLD and LF-LLD commonly had lower caloric and carbohydrate intakes from the diet than their respective control groups. In this study, we found that the presence of live LcS in stool is associated with a healthy gut environment and inhibition of the reactivation of latently infected viruses in the host. However, these health-promoting effects on the host were not related to the frequency of FML intake. Furthermore, dysbiosis of the gut microbiome and diet including caloric intake was related to the viability of ingested LcS in the gut.
\end{abstract}

Keywords: microbiome, live LcS, organic acid profiles, herpes simplex virus, defecatory symptoms

\section{Introduction}

Probiotics are defined as 'Live microorganisms which when administered in adequate amounts confer a health benefit on the host' (Hill et al., 2014) and there have been numerous reports on the effects of probiotics, such as modulation of the gut-brain axis (Westfall et al., 2017; Zhang et al., 2020), host immunity including innate and acquired immune responses (Azad et al., 2018; Giorgetti et al., 2015), the competitive exclusion of pathogens (Kristensen et al., 2016; Rao et al., 2016) and the improvement of defecatory symptoms (Miller et al., 2017). Lacticaseibacillus paracasei (the previous taxonomic nomenclature was Lactobacillus casei) YIT 9029 (strain Shirota: LcS) is a popular probiotic strain, and 40 million fermented milk products containing LcS (FML) are consumed daily throughout the world (www. yakult.co.jp/english/). Several double-blind, placebocontrolled trials have shown the health-promoting effects of LcS, including the preservation of the diversity of the gut microbiome in the stool (Kato-Kataoka et al., 2016), improved sleep quality (Takada et al., 2017), reduced fever duration in elderly people (Kushiro et al., 2019), modified interleukin-12 involved in the enhancement of natural killer cell activity (Takeda et al., 2006), decreased salivary 
levels of secretory immunoglobulin (Ig)A and antimicrobial peptides (Vaisberg et al., 2019) and decreased serum viral antibody indexes (Gleeson et al., 2016). Moreover, several epidemiological studies have also suggested that frequent FML consumption contributes to the normalisation of bowel habits (Aoyagi et al., 2019; Shima et al., 2019) and reduces the risk of hypertension in the elderly (Aoyagi et al., 2017). In most of those reports, the faecal LcS counts were obtained with a quantitative PCR method using an LCS-specific primer set, and the relationships between the faecal LcS counts and these health-promoting effects were discussed. However, since this quantitative PCR cannot distinguish between live and dead LcS, it is unclear whether LcS need to reach the lower gastrointestinal tract alive to have above mentioned health-promoting effects. In these contexts, our aim was to estimate the health-promoting effects of LcS that reached the lower gastrointestinal tract alive in healthy Japanese adults, and we attempted to characterise the gut microbiome, organic acid profiles, defecatory symptoms and serum viral antibody indexes in subjects in which live LcS was detected with the PMAqPCR method.

\section{Materials and methods}

\section{Study design}

The KSO Corporation (Tokyo, Japan) recruited 80 healthy Japanese adults by employing a questionnaire (Supplementary Table S1). This study was conducted in conformity with the Helsinki Declaration, and the study plan was approved by the Human Study Ethics Committee of Nihonbashi Cardiology Clinic, Japan (Approval number NJI-019-01-01, 11 January 2019). All subjects provided written informed consent before they participated in this study. The subjects responded to the questionnaire and had blood taken only once, and the serum fractionated from the blood was used to analyse the viral antibody titer. In addition, subjects also submitted a portion of their stool on the same morning as the blood collection. The stool samples were transported to Yakult Central Institute and used to analyse the gut microbiome and organic acid profiles. Abdominal symptoms, fermented milk products intake, and food intake frequency were investigated by using a questionnaire. Finally, of the 80 subjects that had been recruited, 72 subjects (average age $38.3 \pm 9.0$ years, 52 men, 20 women) were included in the analysis, after the exclusion of 4 subjects who met the exclusion criteria (administration of antibiotics, antiflatulents, or laxatives within 1 week of stool collection), 3 subjects whose questionnaire responses were incorrect and 1 subject for whom insufficient $16 \mathrm{~S}$ rRNA gene reads were detected in subsequent 16S rRNA gene amplicon sequencing.

\section{Sample collection}

Each subject was given a stool collection tube containing $2 \mathrm{ml}$ of RNAlater (Thermo Fisher Scientific KK, Waltham, MA, USA) and two empty stool collection tubes whose weight had been measured beforehand. Subjects introduced about $0.5 \mathrm{~g}$ of fresh stool into the collection tube with a stool collection spoon and then shook this tube vigorously. On receipt, the stool samples were anonymised and transported to Yakult Central Institute (Tokyo, Japan), and stored at $4{ }^{\circ} \mathrm{C}$ until their preparation for analysis. Thirteen $\mathrm{ml}$ of blood was collected from subjects on the same day as the stool submission. Eight $\mathrm{ml}$ of blood was transported to BML Inc. (Tokyo, Japan) and herpes simplex virus (HSV), varicella zoster virus and cytomegalovirus antibody titers were measured using the isolated serum. The remaining $5 \mathrm{ml}$ of serum was transferred to Yakult Central Institute, of which $2 \mathrm{ml}$ of serum was transferred to LSI Medience Corporation (Tokyo, Japan) and the diphtheria antibody titer was measured. The HSV IgG titer was measured at Yakult Central Institute using HSV type 1 IgG enzymelinked immunosorbent assay (ELISA) kit (Phoenix Pharmaceuticals, Burlingame, CA, USA) according to the manufacturer's instructions included in the kit.

\section{Stool sample preparation}

Stool samples were subjected to pretreatment for DNA and RNA extraction according to the method described by Kubota et al. (2010). Each sample without RNAlater was weighed and diluted with phosphate buffered saline (PBS) at a ratio of 1:9. After faecal homogenate (100 $\mathrm{mg}$ faeces/ $\mathrm{ml}$ ) containing $\$ 5.0 \mathrm{~mm}$ zirconia beads was suspended by ShakeMaster (Biomedical Science, Tokyo, Japan) for $10 \mathrm{~min}$ at room temperature, the faecal homogenate was then divided into three new $2 \mathrm{ml}$ tubes (200, 200, $450 \mu \mathrm{l})$. One was washed with PBS and stored at $-80^{\circ} \mathrm{C}$ until DNA extraction. Again, one sample was mixed with $800 \mu \mathrm{l}$ PBS and underwent centrifugation at $13,000 \times g$, for $5 \mathrm{~min}$. The supernatant was then discarded and pellets were stored at $-30{ }^{\circ} \mathrm{C}$ until being treated with propidium monoazide. The $450 \mu$ lof the remaining faecal homogenate was mixed with $50 \mu \mathrm{l}$ of $10 \%(\mathrm{v} / \mathrm{v})$ perchloric acid and incubated for $12 \mathrm{~h}$ at $4{ }^{\circ} \mathrm{C}$ for deproteinization. The deproteinized stool diluent was stored at $-80^{\circ} \mathrm{C}$ prior to measurement of the concentrations of faecal organic acids. On the other hand, the faecal homogenate that was mixed with RNAlater at the time of stool submission was suspended in 9 volumes of RNAlater and mixed with a ShakeMaster for $10 \mathrm{~min}$. Then $200 \mu \mathrm{l}$ of the further 5 -fold diluted suspension was introduced into a $2 \mathrm{ml}$ tube containing $1 \mathrm{ml}$ of PBS. After centrifugation at $13,000 \times g$, for $5 \mathrm{~min}$, the supernatant was discarded, and the remaining pellet was stored at $-80{ }^{\circ} \mathrm{C}$ until RNA extraction. 


\section{Propidium monoazide treatment}

Propidium monoazide (PMA), a DNA-intercalating dye that modifies double-stranded DNA, is highly selective in that it penetrates the cytoplasm of dead bacteria but not that of live bacteria. Quantitative PCR with PMA (PMA-PCR) is utilised as a method for detecting live bacteria based on the PMA properties (Nocker et al., 2006). Fujimoto et al. (2011) also reported that only live LcS can be detected selectively by PMA-PCR. $2 \mu$ of $5 \mathrm{nM}$ PMA (Cosmo Bio Co. Ltd., Tokyo, Japan) was added to a $200 \mu \mathrm{l}$ faecal suspension stored at $-30^{\circ} \mathrm{C}$ to achieve a final concentration of $50 \mu \mathrm{M}$. After being stirred with a Voltex mixer, the faecal suspension was incubated on ice in the dark for $5 \mathrm{~min}$ and was exposed to visible light for $10 \mathrm{~min}$ by using an LED Crosslinker (Takara Bio Inc., Shiga, Japan) (Fujimoto et al., 2008). PMA-treated samples were stored at $-30{ }^{\circ} \mathrm{C}$ until the DNA was extracted.

\section{DNA extraction and measurement of total bacterial counts by quantitative PCR}

DNA extraction and qPCR were performed according to the method described by Matsuki et al. (2004) using an ABI PRISM 7900HT Sequence Detection System (Life Technologies Japan Ltd., Tokyo, Japan). The total bacterial counts were quantified by employing qPCR analysis using primer sets and standard strains according to the method described by Shima et al. (2019). The DNA of faecal samples treated with PMA was extracted with the above methods, and live LcS was measured by qPCR as described by Fujimoto et al. (2008). The detection limit of the PMA-qPCR was about $1 \times 10^{6}$ cells $/ g$ faeces in this study.

\section{Amplification of 16S rRNA gene and sequencing}

DNA was prepared for $16 \mathrm{~S}$ rRNA gene amplicon sequencing according to the Earth Microbiome Project (EMP) protocol (Caporaso et al., 2011, 2012). The concentrations of DNA extracted from stool samples were measured with a NanoDrop 2000c (Thermo Fisher Scientific) and diluted to $10 \mathrm{ng} / \mu \mathrm{l}$. The $\mathrm{V} 1-\mathrm{V} 2$ region of the $16 \mathrm{~S}$ rRNA gene in the diluted DNA samples was amplified using the 27Fmod2 forward primer and the 338R reverse primer, which contains Golay barcode and illumine adapter sequences (Nagara et al., 2017). PCR was performed on an ABI 7500 RealTime PCR System (Thermo Fischer Scientific). The PCR reaction solution $(50 \mu \mathrm{l})$ contained $2 \times \mathrm{TB}$ Green Premix ExTaq (Tli RnaseH plus) (Takara Bio Inc.) (25 $\mu$ l), NucleaseFree Water $(22 \mu \mathrm{l}), 100 \mathrm{nM}$ each primer $(1 \mu \mathrm{l})$, and template DNA $(1 \mu \mathrm{l})$. The PCR conditions were an initial $95^{\circ} \mathrm{C}$ for $30 \mathrm{~s}$, followed by $95{ }^{\circ} \mathrm{C}$ for $5 \mathrm{~s}, 55^{\circ} \mathrm{C}$ for $30 \mathrm{~s}$, and $72{ }^{\circ} \mathrm{C}$ for $40 \mathrm{~s}$. In accordance with previous studies (Matsuki et al., 2016; Nagara et al., 2017), PCR was monitored by using the SYBR signal, and stopped before signal saturation to minimise the bias and erroneous product. The PCR products were purified with an AMPure XP Kit (Beckman Coulter, Brea, CA, USA) and quantified with a Quant-iT PicoGreen dsDNA Kit (Invitrogen, Leek, the Netherlands). The library was constructed by mixing equal amounts of DNA for every sample, and sequenced on a MiSeq System (Illumina, San Diego, CA, USA) using a paired-end $2 \times 250$ bp cycle run and MiSeq Reagent Kits v2 (Illumina). As a result, 6,092,422 amplicon sequence reads were obtained (from 32,149 to 123,527 reads per sample).

\section{Processing of $16 \mathrm{~S}$ rRNA gene sequence data}

The amplicon sequence reads were processed using QIIME 2 (ver. 2019.01, https:// qiime2.org/) (Bolyen et al., 2019). Absolute count data obtained from taxonomic assignment was normalised into relative abundances at the phylum and genus levels using the taxa plugin. The $\alpha$-diversity of the samples was analysed at a sampling depth of 10,000, allowing the retention of 80 samples. Shannon diversity, observed amplicon sequence variants (ASVs), and Faith's phylogenetic diversity indexes were calculated with QIIME2 using the diversity plugin. The number of gut bacteria at the genus level in each subject was calculated by multiplying the total bacterial count determined by quantitative PCR by the compositional data at the genus level obtained by $16 \mathrm{~S}$ rRNA gene amplicon analysis.

\section{RNA extraction and the measurement of the number of gut microbiome in the faeces by RT-qPCR}

Total RNA was extracted from the samples according to the methods described by Matsuda et al. (2007). The extracted RNA samples were stored at $-80{ }^{\circ} \mathrm{C}$ until the gut microbiome were analysed. The counts of 2 genera (Prevotella, Pseudomonas) and 2 species (Clostridium difficile, Clostridium perfringens) were quantified with specific primer sets and total RNA as a template according to the method described by Matsuda et al. (2009). A OneStep RT-PCR Kit (Qiagen GmbH, Hilden, Germany) was used for reverse transcription-quantitative PCR. RTqPCR was performed in a 384-well optical plate on an ABI PRISM 7900HT Sequence Detection System (Thermo Fisher Scientific).

\section{Measurement of HSV antibody titer}

HSV type 1 IgG ELISA kit (Phoenix Pharmaceuticals) was used to measure antibody titers against herpes virus type 1 in the serum. Briefly, the ELISA was performed according to the manufacturer's instructions, and the absorbance of each sample measured at OD $520 \mathrm{~nm}$. The antibody titer of each sample was assessed as HSV-1 IgG index by dividing the mean absorbance of two wells by the absorbance of the calibrator. Absorbance was measured using a SpectraMax 190 Microplate Reader (Molecular Devices, Tokyo, Japan), 
and the index was considered negative at less than 0.9, pseudo-positive at 0.9 to 1.0 , and positive at 1.0 and above. HSV IgM antibody titers, varicella zoster IgM antibody titers and cytomegalovirus IgM antibody titers were sent to BML Inc. for measurement. For each antibody index analysed with an enzyme immunoassay method (Serena et al., 2018), antibody titers below 0.80 were considered negative and those above 0.80 were considered positive. Serum diphtheria IgG antibody titers (IU/ml) were judged positive at $0.01 \mathrm{IU} / \mathrm{ml}$ or higher.

\section{Measurement of the concentration of faecal organic acids}

The organic acid concentrations in faeces were measured as described by Matsumoto et al. (2010). After the deproteinized stool diluent stored at $-80{ }^{\circ} \mathrm{C}$ was filtered with $0.45 \mu \mathrm{m}$ Centricut Ultramini (Kurabo Ltd., Osaka, Japan), the filtrate was subjected to high performance liquid chromatography (Waters, Milford, MA, USA) to measure the concentrations of lactate, acetate, propionate, butyrate, succinate, valerate and isovalerate. The total organic acid concentration in the faeces was calculated by adding together the concentrations of each organic acid.

\section{Questionnaire survey}

The subjects provided basic information (sex, age, height, and weight), the total number of defecations during the week before stool collection, stool consistency on defecation, defecatory symptoms (straining, feeling of incomplete evacuation, or abdominal pain), and lifestyle habits (smoker or non-smoker, weekly frequency of alcohol use/consumption [0-7], weekly frequency of exercise [0-7], and the weekly frequency of consumption of fermented milk with and without LcS for the previous month [0-7]). The Bristol Stool Form Scale (BSFS) was used to evaluate stool consistency (Lewis and Heaton, 1997); the normal range was set at 3.5 to 4.4. The BSFS was evaluated and entered in the questionnaire survey when the subjects collected their faeces. Defecatory symptoms were evaluated on a five-point scale: none (score 0 ), mild (score 1), moderate (score 2), strong (score 3), severe (score 4). The medication status for one week before the start of the study and the time of stool submission was provided in the questionnaire survey, and if the subjects were taking antibiotics, intestinal regulators, or laxatives during that week, they were excluded from the analysis.

\section{Subgroup analysis}

Based on the questionnaire, subjects who ingested LcScontaining fermented milk products 6 times or more per week were categorised as the high-frequency intake group, and subjects who ingested LcS-containing fermented milk products 1 or more and less than 6 times per week were categorised as the low-frequency intake group.
Furthermore, the group for whom live LcS was detected by the PMA-PCR method was categorised as the live LcS detected group, and the group for whom live LcS was not detected was categorised as the live LcS undetected group.

\section{Statistical analysis}

All analyses were performed using R ver.3.6.1 software (https://cran.r-project.org/) (Ihaka and Gentleman, 1996). The unpaired Student's $t$-test or Mann-Whitney $U$-test were used to assess the statistical significance between the two groups. The bacterial counts of the 'not detected' samples were regarded as half the detection limits (logarithm) of the corresponding primer sets. $P<0.05$ was considered statistically significant, and $0.05 \leq P<0.1$ was considered marginally significant.

\section{Results}

\section{Difference of life habits, gut microbiome, defecatory symptoms and viral antibody indexes between subjects}

Age, frequency of FML consumption, and the amount of LcS ingested in the LLD ( $n=60)$ were significantly higher than those in the LLnD $(n=12)$ (Table 1). Gender, height, weight, body mass index, smoking, total energy expenditure through exercise, and sleeping hours were not associated with the detection of Live-LcS in the stool. The weekly frequency of alcohol drinking tended to be lower in the LLD than in the LLnD $(P=0.073)$ (Table 1). The calorie intake and the amount of carbohydrates in the LLD were significantly lower than those in the LLnD form an analysis of dietary habits (calorie intake, $P=0.035$, amount of carbohydrate, $P=0.016$ ) (Table 1 ). The $\beta$-diversity index of the gut microbiome was a statistically significant difference between LLD and LLnD (BrayCurtis, $P=0.023$; Jaccard, $P=0.009$ ) (Supplementary Figure S1A,B). Faith's PD and observed ASVs as the $\alpha$-diversity indicators were significantly higher in the LLD than in the LLnD (Faith's PD, $P=0.021$; observed ASVs, $P=0.020$ ). (Figure 1A,B). The Lactobacillaceae, Bifidobacteriaceae and Coriobacteriaceae counts in the LLD were significantly higher than those in the LLnD (Lactobacillaceae, $P<0.001$; Bifidobacteriaceae, $P=0.009$; Coriobacteriaceae, $P=0.044$ ) (Figure 1C). Further, the total bacterial counts and the Rikenellaceae count tended to be higher in the LLD than in the LLnD (total bacterial count, $P=0.088$; Rikenellaceae, $P=0.062)$, conversely, the Veillonellaceae count tended to be lower in the LLD $(P=0.089)$ (Figure 1C). The Prevotella, Clostridium difficile, Clostridium perfringens, and Pseudomonas counts were not associated with the detection of Live LcS in the stool (Supplementary Table S2). The concentration of succinate was significantly lower in the LLnD than in the LLD $(P=0.039)$ (Figure $1 \mathrm{D})$, and conversely the concentrations of butyrate and valerate tended to be higher (butyrate: $P=0.073$, valerate: 
$P=0.092)$ than in the LLD (Figure 1E,F). No significant differences were observed between the concentrations of total organic acid, acetate, propionate, lactate, isovalerate, and formate in the two groups (Supplementary Table S2). Serum HSV IgG antibody index was not associated with the detection of Live-LcS in the stool (Supplementary Table S2), but HSV IgM antibody index was significantly lower in the LLD than in the LLnD $(P=0.01)$ (Figure 2A). Furthermore, the HSV IgM antibody index in HSV IgGpositive subjects tended to be lower in the LLD $(n=28)$ than in the LLnD $(P=0.063)$ (Figure 2B). The feeling of incomplete evacuation tended to be lower in the LLD than in the LLnD $(P=0.089)$ (Figure 3$)$. No association was found between the number of defecations per week, the interval of defecation, stool consistency, straining at defecation and abdominal pain and Live-LcS detection (Supplementary Table S2).

\section{Impact of life habits, gut microbiome, defecatory symptoms, and viral antibody index in LLD subjects}

To investigate the impact of the frequency of consumption of FML on the gut microbiome and immunoglobulin index against various viruses on the host, various parameters in the Live-LcS-detected subjects $(n=60)$ were compared for the subjects who consumed FML at low $(n=13)$ and high frequencies $(n=47)$ (Supplementary Figure S2). The amount of ingested LcS per day and the frequency of the consumption of FML were significantly higher in the subjects who consumed FML at a high frequency (FML$\mathrm{HF}$ ) than in the subjects who consumed FML at a low frequency (FML-LF) $(P<0.001)$ (Table 2$)$. The age, gender, height, weight, Live-LcS counts in the stool, smoking status, frequency of alcohol use/consumption, and hours of sleep per day were not associated with the frequency of consumption of fermented milk products containing LcS (Table 2). The amount of carbohydrate intake per day tended to be higher in the FML-HF than in the lowfrequency intake group $(P=0.074)$. No differences between the calorie, protein and fat intake per day were found for the FML-HF and FML-HF (Table 2). The total bacterial counts, Alcaligenaceae, Clostridiaceae, Lachnospiraceae, and Ruminococcaceae were significantly lower in the highfrequency intake group than in the low-frequency intake group (total bacterial counts, $P=0.029$; Alcaligenaceae, $P=0.024$; Clostridiaceae, $P=0.037$; Lachnospiraceae, $P=0.006$; Ruminococcaceae, $P=0.038$ ) and Streptococcaceae in the high-frequency intake group tended to be lower than those in the low-frequency intake group $(P=0.069)$ (Figure 4). The Lactobacillaceae counts were significantly higher in the high-frequency intake group than in the lowfrequency intake group $(P=0.031)$. Prevotella, C. difficile,

Table 1. Comparison of background, life habits and dietary habits live-LcS-detected group (LLD) and live-LcS-not detected group (LLnD). ${ }^{1}$

\begin{tabular}{|c|c|c|c|}
\hline Parameter & LLnD & LLD & $P$-value \\
\hline \multicolumn{4}{|l|}{ Background } \\
\hline Number of subjects ( $\mathrm{n}$ ) & 12 & 60 & \\
\hline Age (years) & $33.58 \pm 6.78$ & $39.23 \pm 9.19$ & 0.048 \\
\hline Gender (male/female) & $9 / 3$ & $43 / 17$ & 1.000 \\
\hline Height $(\mathrm{cm})$ & $166.62 \pm 9.03$ & $167.47 \pm 8.62$ & 0.758 \\
\hline Weight (kg) & $66.17 \pm 10.45$ & $65.36 \pm 14.03$ & 0.851 \\
\hline BMI & $23.76 \pm 2.70$ & $23.13 \pm 3.66$ & 0.576 \\
\hline Frequency of consumption of fermented milk products containing LcS (times/week) & $2.50[0.00,12.50]$ & $12.50[1.50,21.00]$ & $<0.001$ \\
\hline Live LCS dose $\left(\times 10^{8}\right.$ cfu/day) & $127.42 \pm 154.69$ & $415.37 \pm 257.63$ & $<0.001$ \\
\hline \multicolumn{4}{|l|}{ Life habits } \\
\hline Smoking status (yes/no) & $2 / 10$ & $9 / 51$ & 1.000 \\
\hline Total energy expenditure by exercise (kcal/month) & $1,775.1 \pm 1,397.5$ & $3,758.3 \pm 6,134.5$ & 0.272 \\
\hline Frequency of alcohol use/consumption (times/week) & $4.5 \pm 2.6$ & $2.9 \pm 2.7$ & 0.073 \\
\hline Sleeping time (h/day) & $6.0 \pm 0.9$ & $6.0 \pm 0.9$ & 0.976 \\
\hline \multicolumn{4}{|l|}{ Dietary habits } \\
\hline Calorie intake (kcal/day) & $2,244.8 \pm 197.6$ & $2,087.8 \pm 236.4$ & 0.035 \\
\hline Carbohydrate (g/day) & $300.2 \pm 42.4$ & $271.3 \pm 36.0$ & 0.016 \\
\hline Protein (g/day) & $86.9 \pm 4.9$ & $83.0 \pm 8.6$ & 0.134 \\
\hline Lipid (g/day) & $64.9 \pm 3.9$ & $62.6 \pm 4.8$ & 0.126 \\
\hline
\end{tabular}


A

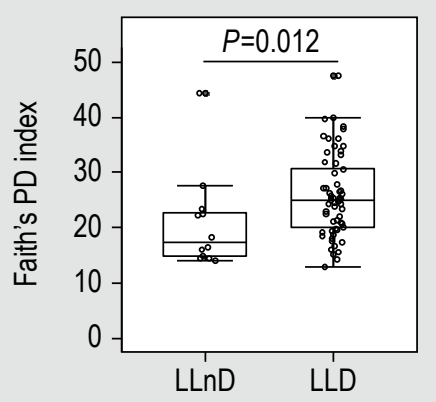

B

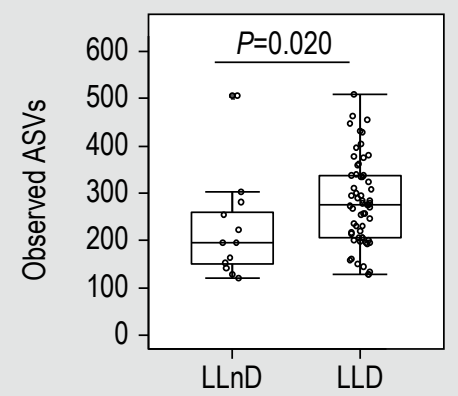

C

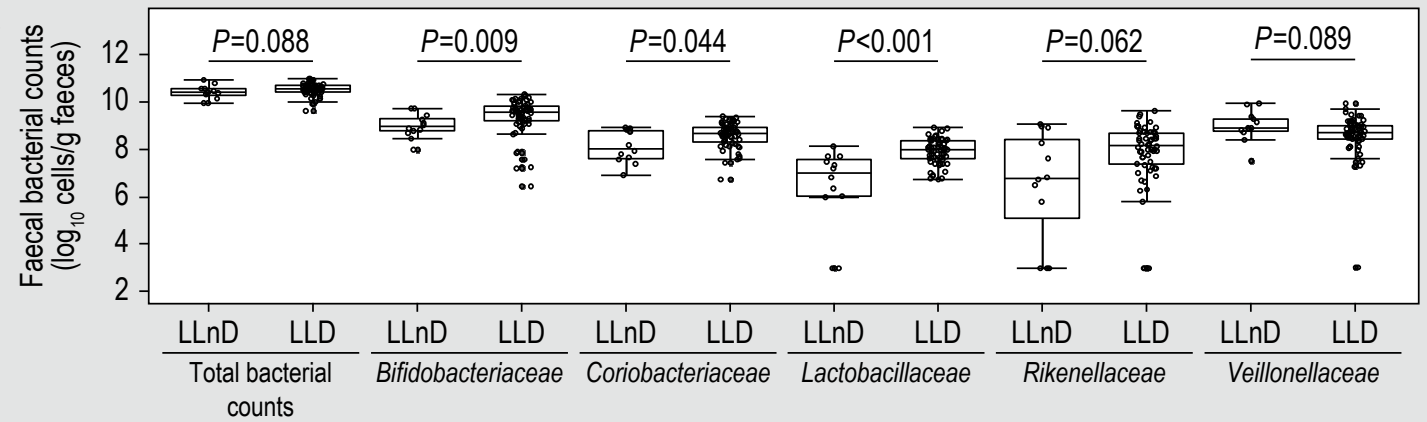

D
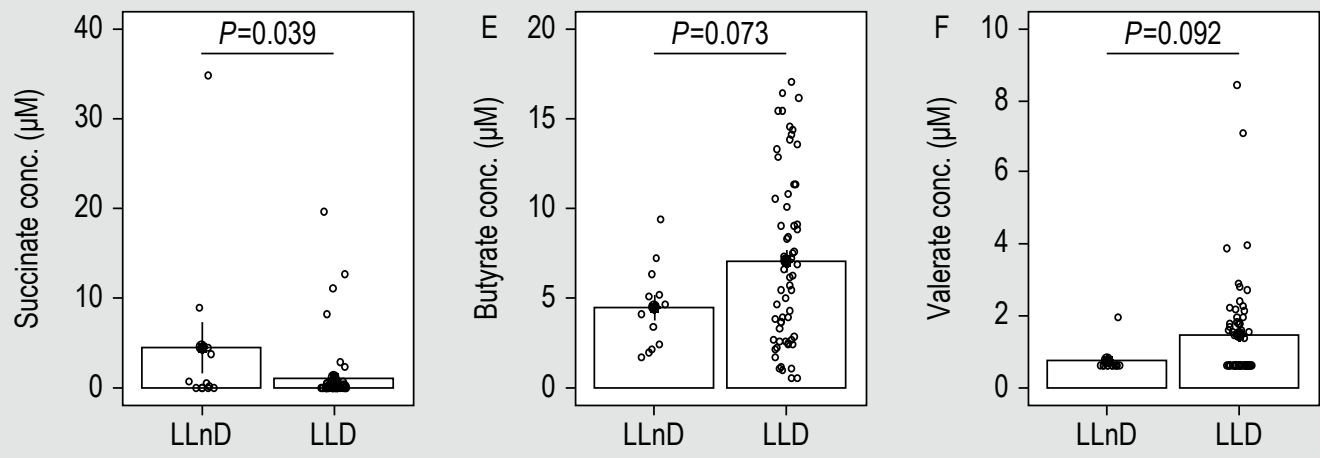

Figure 1. Comparison of gut microbiome and organic acid profiles in subjects between with and without live-LCS detection. (A) Faith's PD index as $\alpha$-diversity, (B) observed ASVs as $\alpha$-diversity, (C) gut microbiome, (D) succinate, (E) butyrate, (F) valerate. Box plots showing differences between LLnD and LLD (A-C). Mann-Whitney U-test was used for statistical analysis of (A-C). Student's $t$-test was used for statistical analysis of $(D-F)$ with $P<0.1$. Total number of subjects $n=72$, LLD = live-LcS-detected group ( $n=60)$, LLnD = live-LcS-not detected group ( $n=12)$. The difference between gut microbiome and organic acid profiles in $L L n D$ and LLD with $P<0.1$ are shown.

C. perfringens, and Pseudomonas were not associated with the frequency of consumption of FML (Supplementary Table S3). Furthermore, there was no association between the FML intake frequency and the number of defecations per week, intervals between defecation, stool consistency, feeling of incomplete evacuation, straining at defecation and abdominal pain (Supplementary Table S3). Serum HSV IgG and IgM antibody index in HSV IgG-positive subjects, and the concentration of each organic acid in the stool were not associated with the FML intake frequency (Supplementary Table S3).
Association between detection of live-LcS in the stool, life habits, gut microbiome, defecatory symptoms and viral antibody index in LF-FML subjects

Two subgroups were set up to exclude interference from the frequency of intake of FML: the LF-LLD $(n=13)$ and the LF-LLnD $(n=6)$ subgroups containing subjects with a low frequency of FML intake ( $<6$ times per week, $n=19$ ). Several biological parameters, such as gut microbiome, concentration of organic acids, viral antibody index and life habits were compared in both groups. The Live-LcS count in the stool and the daily calorie and carbohydrate intake in the LF-LLD subgroup were significantly higher than those in the LF-LLnD subgroup ( $P=0.007$ and $P=0.001)$ (Table 3$)$. 


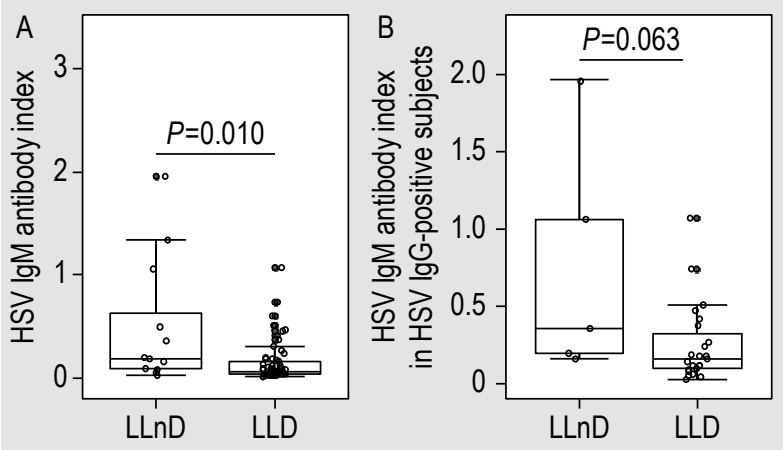

Figure 2. Comparison of serum herpes simplex virus (HSV) antibody index in subjects between with and without live-LcS detection. (A) HSV IgM antibody index, (B) HSV IgM antibody index in HSV IgG positive subjects (total subjects $(n=28)$, LLD $=$ live-LcS-detected group ( $\mathrm{n=23}$ ), LLnD = live-LcS-not detected group $(n=5))$. Box plots showing differences between LLnD and LLD. Mann-Whitney U-test was used for statistical analysis of (A) and (B) with $P<0.1$.

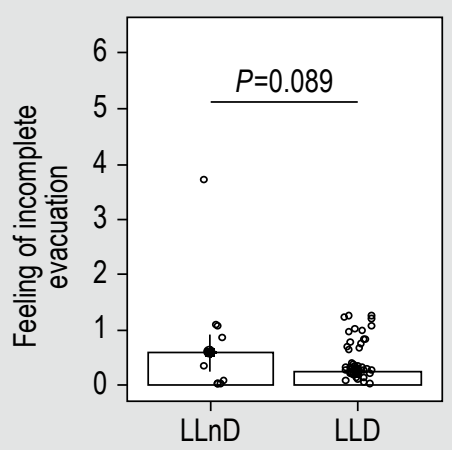

Figure 3. Comparison of defecatory symptoms in subjects between with and without live-LcS detection. Total number of subjects $(n=72)$, LLD = Live-LcS-detected group $(n=60)$, LLnD = Live-LcS-not detected group ( $n=12)$. Box plots showing differences between LLnD and LLD. Student's t-test was used for statistical analysis with $P<0.1$.

Table 2 Comparison of background, life habits and dietary habits between low and high frequency consumption groups of fermented milk products containing LcS (FML-LF and FML-HF). ${ }^{1}$

\begin{tabular}{|c|c|c|c|}
\hline Parameter & FML-LF & FML-HF & $P$-value \\
\hline \multicolumn{4}{|l|}{ General information } \\
\hline Number of Live LcS detected subjects in each group (n) & 13 & 47 & \\
\hline Number of Live LcS-not detected subjects in each group (n) & 12 & 3 & \\
\hline Age (years) & $39.8 \pm 9.7$ & $39.1 \pm 9.2$ & 0.815 \\
\hline Gender (male/female) & $9 / 4$ & $34 / 13$ & 1.000 \\
\hline Height $(\mathrm{cm})$ & $167.3 \pm 8.4$ & $167.5 \pm 8.8$ & 0.930 \\
\hline Weight (kg) & $60.6 \pm 10.8$ & $66.7 \pm 14.6$ & 0.170 \\
\hline BMI & $21.5 \pm 2.3$ & $23.6 \pm 3.9$ & 0.069 \\
\hline Frequency of consumption of fermented milk products containing LcS (times/week) & $3.50[1.50,5.00]$ & $14.00[11.00,21.00]$ & $<0.001$ \\
\hline Live LCS dose ( $\times 10^{8}$ cfu/day) & $121.5 \pm 116.4$ & $496.6 \pm 224.6$ & $<0.001$ \\
\hline \multicolumn{4}{|l|}{ Life habits } \\
\hline Smoking status (yes/no) & $1 / 12$ & $8 / 39$ & 0.668 \\
\hline Total energy expenditure by exercise (kcal/month) & $6,804.7 \pm 9,917.2$ & $2,915.6 \pm 4,388.8$ & 0.272 \\
\hline Frequency of alcohol use/consumption (times/week) & $3.2 \pm 2.8$ & $2.9 \pm 2.7$ & 0.073 \\
\hline Sleeping time (h/day) & $6.0 \pm 0.8$ & $6.0 \pm 0.9$ & 0.976 \\
\hline \multicolumn{4}{|l|}{ Dietary habits } \\
\hline Calorie intake (kcal/day) & $2,014.4 \pm 203.0$ & $2,108.1 \pm 242.8$ & 0.208 \\
\hline Carbohydrate (g/day) & $255.6 \pm 19.6$ & $275.7 \pm 38.4$ & 0.074 \\
\hline Protein (g/day) & $81.9 \pm 8.2$ & $83.3 \pm 8.8$ & 0.598 \\
\hline Lipid (g/day) & $62.6 \pm 5.1$ & $62.6 \pm 4.7$ & 0.995 \\
\hline
\end{tabular}




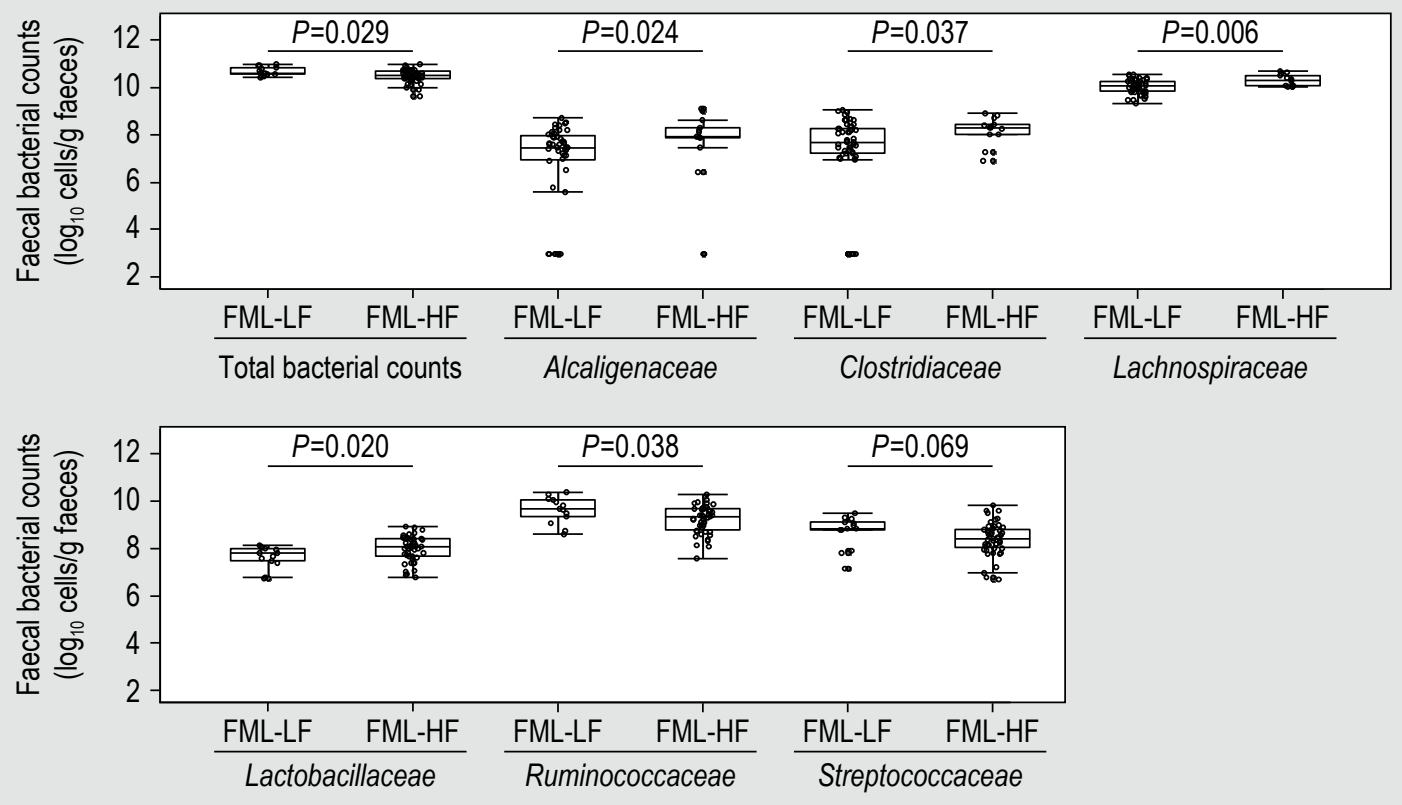

Figure 4. Difference between gut microbiome with low and high frequency consumption of fermented milk products containing LcS in subjects with LcS detected in their stools (FML-LF and FML-HF). Live-LcS detected subjects ( $n=60)$, FML-LF ( $n=13$ ), FML-HF $(n=47)$. The faecal bacterial counts (total bacterial counts, Alcaligenaceae, Clostridiaceae, Lachnospiraceae, Lactobacillaceae, Ruminococcaceae, Streptococcaceae) for FML-LF and FML-HF are shown by box plots with $P<0.1$. The Mann-Whitney U-test was used for statistical analysis.

Table 3. Comparison of background, life habits and dietary habits between low frequency consumers of LcS fermented milk liveLcS-detected (LF-LLD) and live-LcS-not detected (LF-LLnD) groups. ${ }^{1}$

\begin{tabular}{|c|c|c|c|}
\hline Parameter & LF-LLnD & LF-LLD & $P$-value \\
\hline \multicolumn{4}{|l|}{ General information } \\
\hline Number of subjects (n) & 6 & 13 & \\
\hline Age (years) & $37.3 \pm 6.9$ & $39.8 \pm 9.7$ & 0.588 \\
\hline Gender (male/female) & $5 / 1$ & $9 / 4$ & 1.000 \\
\hline Height (cm) & $168.1 \pm 8.8$ & $167.3 \pm 8.4$ & 0.851 \\
\hline Weight (kg) & $67.3 \pm 11.9$ & $60.6 \pm 10.8$ & 0.237 \\
\hline BMI & $23.8 \pm 3.5$ & $21.5 \pm 2.3$ & 0.105 \\
\hline Frequency of consumption of fermented milk products containing LcS (times/week) & $2.50[1.50,3.50]$ & $3.50[1.50,5.00]$ & 0.138 \\
\hline Live LcS dose ( $\times 10^{8}$ cfu/day) & $89.5 \pm 76.3$ & $121.5 \pm 116.4$ & 0.550 \\
\hline \multicolumn{4}{|l|}{ Life habits } \\
\hline Smoking status (yes/no) & $1 / 5$ & $1 / 12$ & 1.000 \\
\hline Total energy expenditure by exercise (kcal/month) & $1,831.0 \pm 1,320.8$ & $6,804.7 \pm 9,917.2$ & 0.153 \\
\hline Frequency of alcohol use/consumption (times/week) & $4.8 \pm 2.6$ & $3.2 \pm 2.8$ & 0.198 \\
\hline Sleeping time (h/day) & $5.9 \pm 1.1$ & $6.0 \pm 0.8$ & 0.893 \\
\hline \multicolumn{4}{|l|}{ Dietary habits } \\
\hline Calorie intake (kcal/day) & $2,281.1 \pm 207.6$ & $2,014.4 \pm 203.0$ & 0.007 \\
\hline Carbohydrate (g/day) & $308.7 \pm 46.0$ & $255.6 \pm 19.6$ & 0.001 \\
\hline Protein (g/day) & $87.3 \pm 5.3$ & $81.9 \pm 8.2$ & 0.096 \\
\hline Lipid (g/day) & $65.2 \pm 4.0$ & $62.6 \pm 5.1$ & 0.223 \\
\hline
\end{tabular}


Age, gender, height, weight, BMI, smoking status, total energy expended through exercise, frequency of alcohol drinking, and sleeping hours were not associated with the Live-LcS detection in the stool among low-frequency consumers of FML $(n=19)$ (Table 3). Faith's PD as the $\alpha$-diversity indicators tended to be higher in the LF-LLD than in the LF-LLnD (Faith's PD, $P=0.096$ ) (Figure 5A). The total bacterial counts, and the Streptococcaceae and Lactobacillaceae counts in the stool in the LF-LLD were significantly higher than those in the LF-LLnD (total bacteria, $P=0.035$; Streptococcaceae, $P=0.018$; Lactobacillaceae, $P=0.028$ ) (Figure 5B). No significant association was found between Live-LcS detection and Prevotella, C. difficile, C. perfringens and Pseudomonas in the subjects who were low-frequency consumers of FML (Supplementary Table S4). The number of defecations per week, the defecation interval, stool consistency, straining at defecation, feeling of incomplete evacuation, and abdominal pain were not associated with Live-LcS detection (Supplementary Table S4) in the subjects who were low-frequency consumers of FML. In addition, serum HSV IgG and IgM antibody, varicella zoster IgG antibody index, diphtheria IgG antibody and cytomegalovirus IgG antibody were not associated with Live-LcS detection in the subjects who were lowfrequency consumers of FML (Supplementary Table S4). The concentration of succinic acid tended to be higher in LF-LLD than in LF-LLnD $(P=0.062)$ (Figure 5C), but the other species of organic acids were not associated with Live-LcS detection in the subjects who were low-frequency consumers of FML (Supplementary Table S4).

\section{Discussion}

In this study, we have estimated the effects of LcS that reached the lower gastrointestinal tract alive on intestinal microbiome, organic acid profiles, defecatory symptoms, and viral antibody indexes in healthy Japanese adults. Our results may provide evidence that live LcS reaching the lower intestinal tract can influence the gut microbiome and viral reactivation in the host.

\section{Characteristic of gut microbiome and organic acid profiles in LLD}

In this study we found higher $\alpha$-diversity of the gut microbiome in the LLD than in the LLnD (Figure 1). Moreover, the Bifidobacteriaceae and Coriobacteriaceae counts in the LLD were significantly higher than in the LLnD (Figure 1). Kato-Kataoka et al. (2016) reported that consumption of FML $\left(1 \times 10^{11} \mathrm{cfu} /\right.$ day, 8 weeks $)$ inhibited the stress-induced reduction in $\alpha$-diversity of the gut microbiome in a placebo-controlled double-blind study in healthy Japanese adults. An increase in the Bifidobacterium count has been reported in subjects with a wide range of ages (Bian et al., 2011; Nagata et al., 2011; Wang et al., 2015). These results indicate that the sum of the counts of dead and live LcS determined by qPCR is associated with the Bifidobacterium count. Interestingly, in this study, the live LcS count measured by PMA-qPCR was also found to be associated with the indigenous bifidobacterial count. In the future, we would like to try to elucidate the mechanism by which live LcS affects the Bifidobacteriaceae count. It has also been reported that the counts of Atopobium clusters, which is a major Coriobacteriaceae group in the human faecal microbiome, is higher in subjects who consume FML more frequently (Aoyagi et al., 2019). Therefore, it is possible that the presence of live LCS in lower gastrointestinal tracts has the ability to increase the $\alpha$-diversity of the gut microbiome and several genera of gut microbiome, such as Bifidobacteriaceae and Coriobacteriaceae in the intestine.
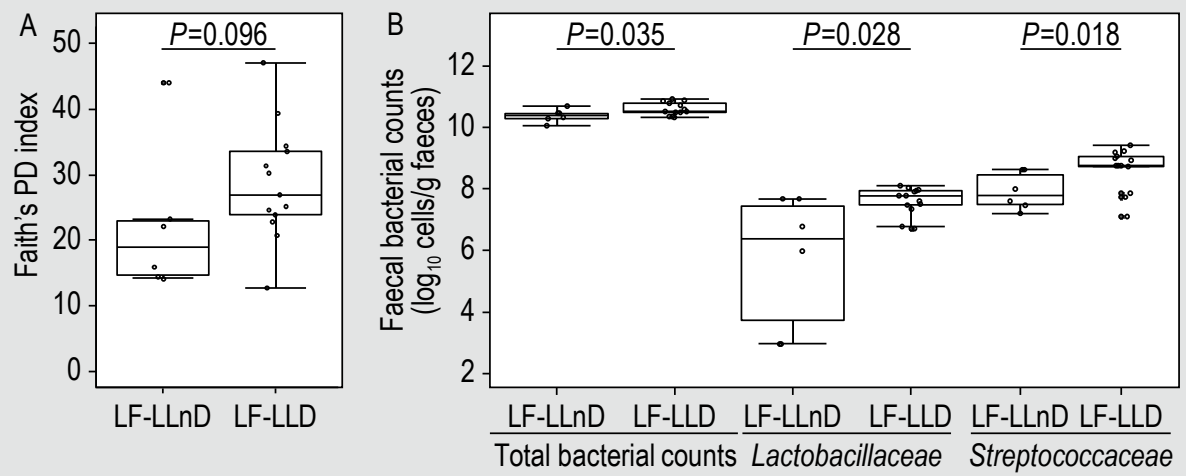

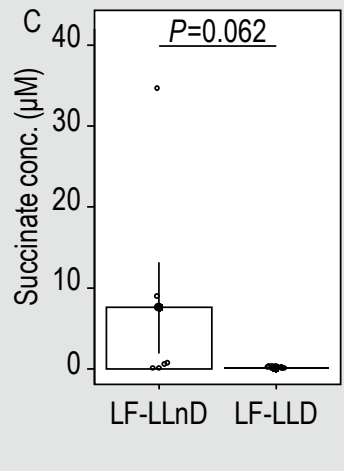

Figure 5. Comparison of gut microbiome and organic acid profiles in subjects with and without live LCS-detected in their stools with a low-frequency consumption of fermented milk products containing LCS. The subjects drank fermented milk products containing LcS low frequency ( $n=19)$, LF-LLD = Live-LcS-detected group ( $n=13)$, LF-LLnD = Live-LcS-not detected group ( $n=6$ ). (A) Faith's PD, (B) Total bacteria counts, Lactobacillaceae, Streptococcaceae. The differences between the gut microbiome (A, $B)$ of LF-LLnD and LF-LLD are shown by box plots with $P<0.1$. (C) Succinate is shown by bar charts with $P<0.1$. A Mann-Whitney $U$-test was used for the statistical analysis of (A) and (B). A Student's $t$-test was used for the statistical analysis of (C). 
The concentrations of the major organic acids in the LLD and LLnD were comparable, however, the concentration of succinate was significantly lower in the LLD than in the LLnD $(P=0.039)$ (Figure 1D-F). The counts of Veillonellaceae, which are succinate-producing bacteria (Serena et al., 2018), was also lower in the LLD than in the LLnD (Figure 1C). Accordingly, the lower Veillonellaceae counts in the LLD may contribute to the lower succinate concentration in the intestine. It has been reported that high concentrations of succinate are associated with the dysbiosis of gut microbiome, associated with inflammatory bowel disease (IBD), and to induce hypoxia-inducible factor $1 \alpha$ in host immune cells, which promotes inflammation (Connors et al., 2018; Tannahill et al., 2013). The causal relationship between Veillonellaceae and the dysbiosis of the gut microbiome in healthy individuals is unclear. However, the Veillonellaceae count, as in IBD patients, may be one of indicators allowing us to assess gut dysbiosis in healthy people. Furthermore, it was reported that the Veillonella count was high in the patients who experienced Crohn's disease complications, children with a high risk of asthma, and children with food allergies (Inoue et al., 2017; Kugathasan et al., 2017; Stokholm et al., 2018). Therefore, the association between gut Veillonella and diseases involving immune abnormalities is very interesting. Further investigations are required into the causal associations between the high colonisation of Veillonellaceae and gut dysbiosis.

From a bird's eye view, the differences in the family level gut bacterial count and faecal organic acid concentration observed when we compared LF-LLnD and LF-LLD showed a very similar pattern to that observed when we compared LLnD and LLD (Supplementary Figure S3). On the other hand, the differences in the patterns of gut microbiome and organic acid profiles observed in the comparison of FMLHF and FML-LF were very different from those observed in the comparison of LLnD and LLD (Supplementary Figure S3). These results suggest that the characteristics of the gut microbiome and organic acid profiles in LLD (Figure 1) are not directly influenced by the high intake of FML but are characteristic of subjects for whom live LcS is detected in the faeces.

The faecal Lactobacillaceae counts were dependent on the frequency of intake of FML (Supplementary Figure S4). Furthermore, the live LcS count in the faeces was significantly positively correlated with the Lactobacillaceae count in the faeces (Spearman's rank correlation coefficient $=0.624 ; P<0.001$, Supplementary Figure S5). This result suggests that the Lactobacillaceae count is strongly dependent on the frequency of FML intake. This result supported the findings described in our previous report (Shima et al., 2019).

\section{Impact on serum viral antibody index of live LcS}

It is known that HSV infection results in a persistently high concentration of HSV specific IgG in the blood and HSV specific IgM increase when persistently latent HSV is reactivated in the host (Whitley and Roizman, 2001). In HSV infection experiments using $\mathrm{T}$ cell defective mice such as nude mice and SCID mice, it has been reported that cellular immunity via $\mathrm{T}$ cells is essential for the elimination of HSV-infected cells (Minagawa and Yanagi, 2000), and an increase in the counts of CD8-positive T cells invading the ganglia inhibits the reactivation of latently infected HSV (Hoshino et al., 2007; Khanna et al., 2003; Liu et al., 2001), suggesting that the immune response in the host may play an important role in maintaining latent HSV infection. LcS has been reported to activate innate immunological effects and T cells in a live LcS-specific manner (Dong et al., 2010; Salas-Lais et al., 2020).

Therefore, in the subjects of this study where HSV IgG was detected in the blood, cellular immunity activated by live LcS may be involved in that the HSV IgM antibody index in the LLD showed a trend lower than those in the LLnD (Figure 2). Although in this study the impact of the HSV antibody titer suggested a characteristic of live $\mathrm{LcS}$, it was already reported that the ingestion of FML has an effect on the cytomegalovirus IgG antibody titer (Gleeson et al., 2016) and the prevention of early infection with influenza A virus (Jung et al., 2017). It has also been suggested that low cytomegalovirus IgG antibody titers and HSV IgG antibody titers may help to maintain a higher level of immune capacity in the host (Gleeson et al., 2016). Therefore, these results raise the possibility that live LcS reaching the gut alive could help to enhance protection against infection by pathogenic viruses and bacteria.

\section{Factors affecting live LcS survive in lower gastrointestinal tracts}

In healthy Singaporeans $(n=21)$ and Australians $(n=25)$, live LcS has been detected by culture methods in all subjects after 2 weeks of LcS intake $\left(1 \times 10^{10-11} \mathrm{cfu} /\right.$ day) (Cox et al., 2019; Khine et al., 2019). In contrast, live LcS was not detected in 3 of 50 subjects in the FML-HF in this study (Table 2). Of these three subjects, Clostridiaceae and Rikenellaceae, which are generally predominant intestinal bacteria, were not detected in one subject. In the remaining two subjects, the total bacterial counts were very low (approximately $1 \times 10^{9}$ cells/g stool), suggesting that all three subjects were suffering from dysbiosis of the gut microbiome. The calorie and carbohydrate intake of the LLD was significantly lower than that of the LLnD (Table 1). In addition, the calorie and carbohydrate intakes were lower in the group in which live $\mathrm{LcS}$ was detected than in LF-LLD and LF-LLnD (Table 3), suggesting a relationship between the detection of live LcS and nutrition. However, 
the causal relationship among these factors is not clear, and further investigation is needed.

\section{Limitations}

This study had several limitations. First, the number of subjects was small and the power was insufficient to perform subgroup analysis. The large difference between the number of subjects and the ratio of males to females for LLD and LLnD may have affected the results. The results obtained in this study may be considered as a preliminary observation. Second, we obtained the gut bacteria count by multiplying the total bacterial count calculated with quantitative PCR by the bacterial composition data at the family level obtained from 16S rRNA gene amplicon analysis. The obtained gut bacteria count may be estimated at less or more than the actual bacteria count, because the copy number of the $16 \mathrm{~S}$ ribosomal RNA gene differs among bacterial species. However, our method provided quantitative data on intestinal bacteria that could not be obtained with the 16S-ribosomal RNA gene amplicon analysis. Finally, in this study, membrane permeability was used as an indicator to distinguish between viable and dead bacteria, but since there are many indicators with which to define viable bacteria, such as culture, residual RNA and enzyme activity, the results may differ depending on which indicator is used.

\section{Conclusions}

The present study has shown that live LcS, one of the most popular probiotics, can reach the lower gastrointestinal tract alive and may affect the gut microbiome, organic acid profiles and inhibit viral reactivation in the host. Moreover, it was shown that the survival of live LcS in the gastrointestinal tract was related to the gut microbiome and diet. These results not only characterise the impacts of live LcS but will also help to advance research on the maintenance and promotion of health by using the characteristics of LcS.

\section{Supplementary material}

Supplementary material can be found online at https://doi. org/10.3920/BM2021.0101.

Figure S1. Bray-Curtis index and Jaccard index as $\beta$-diversity by PCoA clustering analysis of LLnD and LLD characteristics.

Figure S2. Frequency histogram of intake of FML intake of FML-LF and FML-HF in live LcS detected subjects.

Figure S3. Heat map for gut microbiome for LLD and LLnD, LF-LLD and LF-LLnD, or FML-LF and FML-HF.
Figure S4. Correlation between the frequency of consumption of LcS containing fermented milk products and faecal Lactobacillaceae counts by $16 \mathrm{~S}$ rRNA genes amplified products analysis.

Figure S5. Correlation between the faecal LcS counts by the PMA-PCR and faecal Lactobacillaceae counts by $16 \mathrm{~S}$ rRNA genes amplified products analysis.

Table S1. Exclusion criteria for subject recruitment.

Table S2. Comparison of gut microbiome, organic acids profiles, stool frequency, defecatory symptoms and viral antibody indexes in subjects between with and without live LcS detected in stool.

Table S3. Effect of frequency of FML consumption on gut microbiome, organic acids profiles, stool frequency, defecatory symptoms and viral antibody indexes in subjects with live LcS detected in stool.

Table S4. Effect of live LcS detection in stool on gut microbiome, organic acids profiles, stool frequency, defecatory symptoms and viral antibody indexes among subjects with low FML intake.

\section{Acknowledgements}

The authors thank all the participating clinicians for their consistent help. They are grateful to Dr. Osamu Chonan, Mr. Tatsuyuki Hayashi, Ms. Junko Shiinoki, Ms. Kaoru Iwazaki, Ms. Hiroko Shigemura, and Mr. Tomoki Igarashi for active help and discussions during this study.

\section{Conflict of interest}

This study was supported by a grant from the Yakult Honsha Co., Ltd. All the authors are employed by Yakult Honsha Co., Ltd.

\section{References}

Aoyagi, Y., Amamoto, R., Park, S., Honda, Y., Shimamoto, K., Kushiro, A., Tsuji, H., Matsumoto, H., Shimizu, K., Miyazaki, K., Matsubara, S. and Shephard, R.J., 2019. Independent and interactive effects of habitually ingesting fermented milk products containing Lactobacillus casei strain Shirota and of engaging in moderate habitual daily physical activity on the intestinal health of older people. Frontiers in Microbiology 10: 1477. https://doi.org/10.3389/ fmicb.2019.01477

Aoyagi, Y., Park, S., Matsubara, S., Honda, Y., Amamoto, R., Kushiro, A., Miyazaki, K. and Shephard, R.J., 2017. Habitual intake of fermented milk products containing Lactobacillus casei strain Shirota and a reduced risk of hypertension in older people. Beneficial Microbes 8: 23-29. https://doi.org/10.3920/BM2016.0135 
Azad, M.A.K., Sarker, M. and Wan, D., 2018 immunomodulatory effects of probiotics on cytokine profiles. BioMed Research International 2018: 8063647. https://doi.org/10.1155/2018/8063647

Bian, L., Nagata, S., Asahara, T., Rahman, M.S., Ohta, T., Yuki, N., Wang, S., Takano, K., Daibo, M. and Nomoto, K. and Yamashiro, Y., 2011. Effects of continuous intake of Lactobacillus casei strain Shirota-fermented milk on risk management of long-term inpatients at health service facilities for the elderly. International Journal of Probiotics and Prebiotics 6: 123-131.

Bolyen, E., Rideout, J.R., Dillon, M.R., Bokulich, N.A., Abnet, C.C., AlGhalith, G.A., Alexander, H., Alm, E.J., Arumugam, M., Asnicar, F., Bai, Y., Bisanz, J.E., Bittinger, K., Brejnrod, A., Brislawn, C.J., Brown, C.T., Callahan, B.J., Caraballo-Rodríguez, A.M., Chase, J., Cope, E.K., Da Silva, R., Diener, C., Dorrestein, P.C., Douglas, G.M., Durall, D.M., Duvallet, C., Edwardson, C.F., Ernst, M., Estaki, M., Fouquier, J., Gauglitz, J.M., Gibbons, S.M., Gibson, D.L., Gonzalez, A., Gorlick, K., Guo, J., Hillmann, B., Holmes, S., Holste, H., Huttenhower, C., Huttley, G.A., Janssen, S., Jarmusch, A.K., Jiang, L., Kaehler, B.D., Kang, K.B., Keefe, C.R., Keim, P., Kelley, S.T., Knights, D., Koester, I., Kosciolek, T., Kreps, J., Langille, M.G.I., Lee, J., Ley, R., Liu, Y.X., Loftfield, E., Lozupone, C., Maher, M., Marotz, C., Martin, B.D., McDonald, D., McIver, L.J., Melnik, A.V., Metcalf, J.L., Morgan, S.C., Morton, J.T., Naimey, A.T., Navas-Molina, J.A., Nothias, L.F., Orchanian, S.B., Pearson, T., Peoples, S.L., Petras, D., Preuss, M.L., Pruesse, E., Rasmussen, L.B., Rivers, A., Robeson, M.S $2^{\text {nd }}$., Rosenthal, P., Segata, N., Shaffer, M., Shiffer, A., Sinha, R., Song, S.J., Spear, J.R., Swafford, A.D., Thompson, L.R., Torres, P.J., Trinh, P., Tripathi, A., Turnbaugh, P.J., Ul-Hasan, S., van der Hooft, J.J.J., Vargas, F., Vázquez-Baeza, Y., Vogtmann, E., von Hippel, M., Walters, W., Wan, Y., Wang, M., Warren, J., Weber, K.C., Williamson, C.H.D., Willis, A.D., Xu, Z.Z., Zaneveld, J.R., Zhang, Y., Zhu, Q., Knight, R., and Caporaso, J.G., 2019. Reproducible, interactive, scalable and extensible microbiome data science using QIIME 2. Nature Biotechnology. 37: 852-857. https://doi.org/10.1038/ s41587-019-0252-6

Caporaso, J.G., Lauber, C.L., Walters, W.A., Berg-Lyons, D., Huntley, J., Fierer, N., Owens, S.M., Betley, J., Fraser, L., Bauer, M., Gormley, N., Gilbert, J.A., Smith, G. and Knight, R., 2012. Ultra-high-throughput microbial community analysis on the Illumina HiSeq and MiSeq platforms. ISME Journal 6: 1621-1624. https://doi.org/10.1038/ ismej. 2012.8

Caporaso, J.G., Lauber, C.L., Walters, W.A., Berg-Lyons, D., Lozupone, C.A., Turnbaugh, P.J, Fierer, N. and Knight, R., 2011. Global patterns of $16 \mathrm{~S}$ rRNA diversity at a depth of millions of sequences per sample. Proceedings of the National Academy of Sciences of the USA 108: 4516-4522. https://doi.org/1073/pnas.1000080107

Connors, J., Dawe, N. and Van Limbergen, J., 2018. The role of succinate in the regulation of intestinal inflammation. Nutrients 11: 25. https:// doi.org/10.3390/nu11010025

Cox, A.J., Makino, H., Cripps, A.W. and West, N.P., 2019. Recovery of Lactobacillus casei strain Shirota (LcS) from faeces with 14 days of fermented milk supplementation in healthy Australian adults. Asia Pacific Journal of Clinical Nutrition 28: 734-739. https://doi. org/10.6133/apjcn.201912_28(4).0009
Dong, H., Rowland, I., Tuohy, K.M., Thomas, L.V. and Yaqoob, P., 2010. Selective effects of Lactobacillus casei Shirota on T cell activation, natural killer cell activity and cytokine production. Clinical and Experimental Immunology 161: 378-388. https://doi. org/10.1111/j.1365-2249.2010.04173.x

Fujimoto, J., Matsuki, T., Sasamoto, M., Tomii, Y. and Watanabe, K., 2008. Identification and quantification of Lactobacillus casei strain Shirota in human feces with strain-specific primers derived from randomly amplified polymorphic DNA. International Journal of Food Microbiology 126: 210-215. https://doi.org/10.1016/j. ijfoodmicro.2008.05.022

Fujimoto, J., Tanigawa, K., Kudo, Y., Makino, H. and Watanabe, K., 2011. Identification and quantification of viable Bifidobacterium breve strain Yakult in human faeces by using strain-specific primers and propidium monoazide. Journal of Applied Microbiology 110: 209-217. https://doi.org/10.1111/j.1365-2672.2010.04873.x

Gleeson, M., Bishop, N.C. and Struszczak, L., 2016. Effects of Lactobacillus casei Shirota ingestion on common cold infection and herpes virus antibodies in endurance athletes: a placebo-controlled, randomized trial. European Journal of Applied Physiology 116: 1555-1563. https://doi.org/10.1007/s00421-016-34.15-x

Giorgetti, G., Brandimarte, G., Fabiocchi, F., Ricci, S., Flamini, P., Sandri, G., Trotta, M.C., Elisei, W., Penna, A., Lecca, P.G., Picchio, M. and Tursi, A., 2015. Interactions between innate immunity, microbiota, and probiotics. Journal of Immunology Research 2015: 501361. https://doi.org/10.1155/2015/501361.

Hill, C., Guarner, F., Reid, G., Gibson, G.R., Merenstein, D.J., Pot, B., Morelli, L., Canani, R.B., Flint, H.J., Salminen, S., Calder, P.C. and Sanders, M.E., 2014. Expert consensus document. The International Scientific Association for Probiotics and Prebiotics consensus statement on the scope and appropriate use of the term probiotic. Nature Reviews Gastroenterology and Hepatology 11: 506-514. https://doi.org/10.1038/nrgastro.2014.66

Hoshino, Y., Pesnicak, L., Cohen, J.I. and Straus, S.E., 2007. Rates of reactivation of latent herpes simplex virus from mouse trigeminal ganglia ex vivo correlate directly with viral load and inversely with number of infiltrating CD8+ T cells. Journal of Virology 81: 81578164. https://doi.org/10.1128/JVI.00474-07

Ihaka, R. and Gentleman, R., 1996. R: a language for data analysis and graphics. Journal of Computational Graphical Statistics 5: 299-314. https://doi.org/10.2307/1390807

Inoue, R., Sawai, T., Sawai, C., Nakatani, M., Romero-Pérez, GA., Ozeki, M., Nonomura, K. and Tsukahara, T., 2017 A preliminary study of gut dysbiosis in children with food allergy Bioscience, Biotechnology, and Biochemistry. 81: 2396-2399. https://doi.org/ 10.1080/09168451.2017.1383849

Jung, Y.J., Lee, Y.T., Ngo, V.L., Cho, Y.H., Ko, E.J., Hong, S.M., Kim, K.H., Jang, J.H., Oh, J.S., Park, M.K., Kim, C.H., Sun, J. and Kang, S.M., 2017. Heat-killed Lactobacillus casei confers broad protection against influenza A virus primary infection and develops heterosubtypic immunity against future secondary infection. Scientific Reports 7: 17360. https://doi.org/10.1038/s41598-017-17487-8 
Kato-Kataoka, A., Nishida, K., Takada, M., Kawai, M., KikuchiHayakawa, H., Suda, K., Ishikawa, H., Gondo, Y., Shimizu, K., Matsuki, T., Kushiro, A., Hoshi, R., Watanabe, O., Igarashi, T., Miyazaki, K., Kuwano, Y. and Rokutan, K., 2016. Fermented milk containing Lactobacillus casei strain Shirota preserves the diversity of the gut microbiota and relieves abdominal dysfunction in healthy medical students exposed to academic stress. Applied and Environmental Microbiology 82: 3649-3658. https://doi.org/10.1128/ AEM.04134-15

Khanna, K.M., Bonneau, R.H., Kinchington, P.R. and Hendricks, R.L., 2003. Herpes simplex virus-specific memory CD8+ T cells are selectively activated and retained in latently infected sensory ganglia. Immunity 18: 593-603. https://doi.org/10.1016/s10747613(03)00112-2

Khine, W.W.T., Ang, X.J., Chan, Y.S., Lee, W.Q., Quek, S.Y., Tan, S.H., Teo, H.T.A., Teo, J.K.B., Lau, Q.C. and Lee, Y.K., 2019. Recovery of Lactobacillus casei strain Shirota (LcS) from faeces of healthy Singapore adults after intake of fermented milk. Beneficial Microbes 10: 721-728. https://doi.org/10.3920/BM2018.0173

Kristensen, N.B., Bryrup, T., Allin, K.H., Nielsen, T., Hansen, T.H. and Pedersen, O., 2016. Alterations in fecal microbiota composition by probiotic supplementation in healthy adults: a systematic review of randomized controlled trials. Genome Medicine 8: 52. https:// doi.org/10.1186/s13073-016-0300-5

Kubota, H., Tsuji, H., Matsuda, K., Kurakawa, T., Asahara, T. and Nomoto, K., 2010. Detection of human intestinal catalase-negative, Gram-positive cocci by rRNA-targeted reverse transcription-PCR. Applied and Environmental Microbiology 76: 5440-5451. https:// doi.org/10.1128/AEM.03132-09

Kugathasan, S., Denson, L.A., Walters, T.D., Kim, M.O., Marigorta, U.M., Schirmer, M., Mondal, K., Liu, C., Griffiths, A., Noe, J.D., Crandall, W.V., Snapper, S., Rabizadeh, S., Rosh, J.R., Shapiro, J.M., Guthery, S., Mack, D.R., Kellermayer, R., Kappelman, M.D., Steiner, S., Moulton, D.E., Keljo, D., Cohen, S., Oliva-Hemker, M., Heyman, M.B., Otley, A.R., Baker, S.S., Evans, J.S., Kirschner, B.S., Patel, A.S., Ziring, D., Trapnell, B.C., Sylvester, F.A., Stephens, M.C., Baldassano, R.N., Markowitz, J.F., Cho, J., Xavier, R.J., Huttenhower, C., Aronow, B.J., Gibson, G., Hyams, J.S. and Dubinsky, M.C., 2017. Prediction of complicated disease course for children newly diagnosed with Crohn's disease: a multicentre inception cohort study. The Lancet 389: 1710-1718. https://doi.org/10.1016/S0140-6736(17)30317-3

Kushiro, A., Shimizu, K., Takada, T., Kusunoki, I. and Aiba, N., 2019. Decreased number of days of fever detection and duration of fever with continuous intake of a fermented milk drink: a randomized, double-blind, placebo-controlled study of elderly nursing home residents. Bioscience of Microbiota, Food and Health 38: 151-157. https://doi.org/10.12938/bmfh.18-024

Lewis, S.J. and Heaton, K.W., 1997. Stool form scale as a useful guide to intestinal transit time. Scandinavian Journal of Gastroenterology 32: 920-924. https://doi.org/10.3109/00365529709011203

Liu, T., Khanna, K.M., Carriere, B.N. and Hendricks, R.L., 2001. Gamma interferon can prevent herpes simplex virus type 1 reactivation from latency in sensory neurons. Journal of Virology 75: 11178-11184. https://doi.org/10.1128/JVI.75.22.11178-11184.2001
Matsuda, K., Tsuji, H., Asahara, T., Kado, Y. and Nomoto, K., 2007. Sensitive quantitative detection of commensal bacteria by rRNAtargeted reverse transcription-PCR. Applied and Environmental Microbiology 73: 32-39. https://doi.org/10.1128/AEM.01224-06

Matsuda, K., Tsuji, H., Asahara, T., Matsumoto, K., Takada, T. and Nomoto, K., 2009. Establishment of an analytical system for the human fecal microbiota, based on reverse transcription-quantitative PCR targeting of multicopy rRNA molecules. Applied and Environmental Microbiology 75: 1961-1969. https://doi.org/10.1128/ AEM.01843-08

Matsuki, T., Watanabe, K., Fujimoto, J., Kado, Y., Takada, T., Matsumoto, K. and Tanaka, R., 2004. Quantitative PCR with 16S rRNA-gene-targeted species-specific primers for analysis of human intestinal bifidobacteria. Applied and Environmental Microbiology 70: 167-173. https://doi.org/10.1128/AEM.70.1.167-173.2004

Matsuki, T., Yahagi, K., Mori, H., Matsumoto, H., Hara, T., Tajima, S., Ogawa, E., Kodama, H., Yamamoto, K., Yamada, T., Matsumoto, S. and Kurokawa, K., 2016. A key genetic factor for fucosyllactose utilization affects infant gut microbiota development. Nature Communications 7: 11939. https://doi.org/10.1038/ncomms11939

Matsumoto, K., Takada, T., Shimizu, K., Moriyama, K., Kawakami, K., Hirano, K., Kajimoto, O. and Nomoto, K., 2010. Effects of a probiotic fermented milk beverage containing Lactobacillus casei strain Shirota on defecation frequency, intestinal microbiota, and the intestinal environment of healthy individuals with soft stools. Journal of Bioscience and Bioengineering 110: 547-552. https://doi. org/10.1016/j.jbiosc.2010.05.016

Miller, L.E., Ouwehand, A.C. and Ibarra, A., 2017. Effects of probiotic-containing products on stool frequency and intestinal transit in constipated adults: systematic review and meta-analysis of randomized controlled trials. Annals of Gastroenterology 30: 629-639. https://doi.org/10.20524/aog.2017.0192

Minagawa, H. and Yanagi, Y., 2000. Latent herpes simplex virus-1 infection in SCID mice transferred with immune CD4+T cells: a new model for latency. Archives of Virology 145: 2259-2272. https:// doi.org/10.1007/s007050070019

Nagara, Y., Takada, T., Nagata, Y., Kado, S. and Kushiro, A., 2017. Microscale spatial analysis provides evidence for adhesive monopolization of dietary nutrients by specific intestinal bacteria. PLoS ONE 12: e0175497. https://doi.org/10.1371/journal. pone.0175497

Nagata, S., Asahara, T., Ohta, T., Yamada, T., Kondo, S., Bian, L., Wang, C., Yamashiro, Y. and Nomoto, K., 2011. Effect of the continuous intake of probiotic-fermented milk containing Lactobacillus casei strain Shirota on fever in a mass outbreak of norovirus gastroenteritis and the faecal microflora in a health service facility for the aged. British Journal of Nutrition 106: 549-556. https://doi.org/10.1017/ S000711451100064X

Nocker, A., Cheung, C.Y. and Camper, A.K., 2006. Comparison of propidium monoazide with ethidium monoazide for differentiation of live vs. dead bacteria by selective removal of DNA from dead cells. Journal of Microbiological Methods 67: 310-320. https://doi. org/10.1016/j.mimet.2006.04.015 
Rao, S.C., Athalye-Jape, G.K., Deshpande, G.C., Simmer, K.N. and Patole, S.K., 2016. Probiotic supplementation and late-onset sepsis in preterm infants: a meta-analysis. Pediatrics 137: e20153684. https://doi.org/10.1542/peds.2015-3684

Salas-Lais, A.G., Robles-Contreras, A., Balderas-López, J.A. and Bautista-de Lucio, V.M., 2020. Immunobiotic and paraprobiotic potential effect of Lactobacillus casei in a systemic toxoplasmosis murine model. Microorganisms 8: 113. https://doi.org/10.3390/ microorganisms 8010113

Serena, C., Ceperuelo-Mallafré, V., Keiran, N., Queipo-Ortuño, M.I., Bernal, R., Gomez-Huelgas, R., Urpi-Sarda, M., Sabater, M., Pérez-Brocal, V., Andrés-Lacueva, C., Moya, A., Tinahones, F.J., Fernández-Real, J.M., Vendrell, J. and Fernández-Veledo, S., 2018. Elevated circulating levels of succinate in human obesity are linked to specific gut microbiota. ISME Journal 12: 1642-1657. https://doi. org/10.1038/s41396-018-0068-2

Shima, T., Amamoto, R., Kaga, C., Kado, Y., Sasai, T., Watanabe, O., Shiinoki, J., Iwazaki, K., Shigemura, H. and Tsuji, H., 2019. Association of life habits and fermented milk intake with stool frequency, defecatory symptoms and intestinal microbiota in healthy Japanese adults. Beneficial Microbes 10: 841-854. https:// doi.org/10.3920/BM2019.0057

Stokholm, J., Blaser, M.J., Thorsen, J., Rasmussen, M.A., Waage, J., Vinding, R.K., Schoos, A.M., Kunøe, A., Fink, N.R., Chawes, B.L., Bønnelykke, K., Brejnrod, A.D., Mortensen, M.S., AlSoud, W.A., Sørensen, S.J. and Bisgaard, H., 2018. Maturation of the gut microbiome and risk of asthma in childhood. Nature Communications 9: 141. https://doi.org/10.1038/s41467-01702573-2

Takada, M., Nishida, K., Gondo, Y., Kikuchi-Hayakawa, H., Ishikawa, H., Suda, K., Kawai, M., Hoshi, R., Kuwano, Y., Miyazaki, K. and Rokutan, K., 2017. Beneficial effects of Lactobacillus casei strain Shirota on academic stress-induced sleep disturbance in healthy adults: a double-blind, randomised, placebo-controlled trial. Beneficial Microbes 8: 153-162. https://doi.org/10.3920/ BM2016.0150
Takeda, K., Suzuki, T., Shimada, S.I., Shida, K., Nanno, M. and Okumura, K., 2006. Interleukin-12 is involved in the enhancement of human natural killer cell activity by Lactobacillus casei Shirota. Clinical and Experimental Immunology 146: 109-115. https://doi. org/10.1111/j.1365-2249.2006.03165.x

Tannahill, G.M., Curtis, A.M., Adamik, J., Palsson-McDermott, E.M., McGettrick, A.F., Goel, G., Frezza, C., Bernard, N.J., Kelly, B., Foley, N.H., Zheng, L., Gardet, A., Tong, Z., Jany, S.S., Corr, S.C., Haneklaus, M., Caffrey, B.E., Pierce, K., Walmsley, S., Beasley, F.C., Cummins, E., Nizet, V., Whyte, M., Taylor, C.T., Lin, H., Masters, S.L., Gottlieb, E., Kelly, V.P., Clish, C., Auron, P.E., Xavier, R.J. and O'Neill, L.A., 2013. Succinate is an inflammatory signal that induces IL-1beta through HIF-1alpha. Nature 496: 238-242. https://doi. org/10.1038/nature11986

Vaisberg, M., Paixao, V., Almeida, E.B., Santos, J.M.B., Foster, R., Rossi, M., Pithon-Curi, T.C., Gorjao, R., Momesso, C.M., Andrade, M.S., Araujo, J.R., Garcia, M.C., Cohen, M., Perez, E.C., Santos-Dias, A., Vieira, R.P. and Bachi, A.L.L., 2019. Daily intake of fermented milk containing Lactobacillus casei Shirota (Lcs) modulates systemic and upper airways immune/inflammatory responses in marathon runners. Nutrients 11: 1678. https://doi.org/10.3390/nu11071678

Wang, C., Nagata, S., Asahara, T., Yuki, N., Matsuda, K., Tsuji, H., Takahashi, T., Nomoto, K. and Yamashiro, Y., 2015. Intestinal microbiota profiles of healthy pre-school and school-age children and effects of probiotic supplementation. Annals of Nutrition and Metabolism 67: 257-266. https://doi.org/10.1159/000441066

Westfall, S., Lomis, N., Kahouli, I., Dia, S.Y., Singh, S.P. and Prakash, S., 2017. Microbiome, probiotics and neurodegenerative diseases: deciphering the gut brain axis. Cellular and Molecular Life Sciences 74: 3769-3787. https://doi.org/10.1007/s00018-017-2550-9

Whitley, R.J. and Roizman, B., 2001. Herpes simplex virus infections. The Lancet 357: 1513-1518. https://doi.org/10.1016/S01406736(00)04638-9

Zhang, P., Wu, X., Liang, S., Shao, X., Wang, Q., Chen, R., Zhu, W., Shao, C., Jin, F. and Jia, C., 2020. A dynamic mouse peptidome landscape reveals probiotic modulation of the gut-brain axis. Science Signaling 13: eabb0443. https://doi.org/10.1126/scisignal.abb0443 